\title{
Contemporary overview of soil creep phenomenon
}

\author{
Łukasz Kaczmarek*, Paweł Dobak \\ Faculty of Geology, University of Warsaw, Żwirki i Wigury 93, 02-089 Warszawa, \\ *corresponding author: lukasz.kaczmarek@uw.edu.pl
}

Received: $8^{\text {th }}$ February, 2017

Accepted: $8^{\text {th }}$ May, 2017

\begin{abstract}
Soil creep deformation refers to phenomena which take place in many areas and research in this field of science is rich and constantly developing. The article presents an analysis of the literature on soil creep phenomena. In light of the complexity of the issues involved and the wide variety of perspectives taken, this attempt at systematization seeks to provide a reliable review of current theories and practical approaches concerning creep deformation. The paper deals with subjects such as definition of creep, creep genesis, basic description of soil creep dynamics deformation, estimation of creep capabilities, various fields of creep occurrence, and an introduction to creep modeling. Furthermore, based on this analysis, a new direction for research is proposed.
\end{abstract}

Key words: constant stress, strain rate, time dependency, creep, clay

\section{Basic definition of creep}

Presently, there are many interpretations of soil strain rate under constant non-failure stress regime (e.g.: Kuhn and Mitchell, 1993; Le et al., 2012; Fatahi et al., 2013; Grimstad et al., 2016). It should be emphasized that the soil creep rate can vary with both time and stress level. Unfortunately, despite many attempts at clarification, there is still no explanation of the reasons for soil creep movement and, hence, the definition of creep is general. The term creep is connected in the soil mechanic's background with Terzaghi's theory of onedimensional consolidation of soils, which is based on excess pore water pressure dissipation. The evaluation of creep role during one - dimensional consolidation process is principal issue for an accurate prognosis of settlement versus time (Vu Cao Minh, 1977). The permeability aspect determining this process enables to apply the scale of time based on relation between time and soil thickness in laboratory and field conditions. Numerous tests and analysis show that evaluation of proper, constant consolidation coefficient value $c_{v}$ is difficult and we can obtain that theoretical state only for a part of observed strain course (Dobak and Gaszyński, 2015). Structural conditions in natural state of soil caused that mobilization of pore water pressure is delayed after new step of loading. The first phase of strain depends significantly on creep properties of soil. The seepage phase of consolidation process can be derived from dependence between $\log c_{v}$ vs. consolidation ratio U (Dobak, 1986; 1999). Numerous tests show straight, constant line response to the middle part of the strain course and significant decrease in the final part. This nonlinearity shows the increasing impact of creep. The last creep phase of consolidation process is assumed after quasi-full dissipation of pore water pressure as well. The secondary consolidation coefficient for this phase is difficult for clear-cut estimation, especially in 
soft mineral clays or organic soils (peats). Linearity assumption $\Delta \mathrm{e} / \Delta \log \mathrm{cannot}$ be reflected for each type of soils and different loading conditions.

The course of strain were carefully studied by Vu Cao Minh (1977) as the impact of different program of incremental loading. Careful analysis of strain course and changes of strain rate enable him to define the general relationship expressed by equation (1):

$\log \dot{\varepsilon}=m \lg \left(\varepsilon_{\infty}-\varepsilon\right)+\lg \left(\frac{1}{\beta}\right)$,

where:

$\varepsilon$ - linear strain,

$\dot{\varepsilon}-$ strain rate,

$\varepsilon_{\infty}$ - definite strain (evaluated at conventional value of little rate of strain),

$m, \beta$-parameters estimated from straight line regression of experimental data.

Analysis of tests results show, that dimensionless parameter $m$ depends on type of soil, especially size of soil grains and particles. Values of $\beta$ parameter depend on relation between loading increment: $\Delta \mathrm{p} / \mathrm{p}_{0}$. Appling this dependence and parameters $m, \beta$ lets to develop consolidation equation as follow (2):

$\frac{\partial^{2} U}{\partial Z^{2}}=\left[\frac{\gamma_{w} H^{2}}{k M_{0}} \cdot \frac{1}{\beta}\left(\frac{\Delta p}{M_{0}}\right)^{m-1}\right](U-S)^{m}$,

where:

$U$ - degree of pore pressure dissipation,

$S$ - degree of settlement (consolidation),

$Z$-dimensionless vertical coordinate,

$\gamma_{w}$ - unit weight of water,

$H$ - length of drainage path,

$k$ - permeability,

$M_{0}$ - constrained modulus,

$\Delta p$ - load increment.

This equation explains relation between seepage and creep. The factor $\frac{\gamma_{w} H^{2}}{k M_{0}}$ is responsible for dissipation of pore water pressure (seepage aspect of consolidation). Then factor $\frac{1}{\beta}\left(\frac{\Delta p}{M_{0}}\right)^{m-1}$ let to describe velocity of strain caused by creep, when pore water have a little participation in sharing the load. Seepage factor is dominating while the high drainage path coexist with the little value of $k$. The creep factor is connected with higher permeability and the short path of drainage (Vu Cao Minh, 1977).

The rheological factor of consolidation can be observed in one-dimensional laboratory tests performed by Dobak and Gaszyński, 2015. The first phase of total compression is due to the change in volume of the sample, mainly through water expulsion from soil pores and the transfer of load to soil particles. This phase is termed primary compression or consolidation. In this context creep, termed hire as secondary compression or consolidation, is assigned to the remaining part of total compression (Fatahi et al., 2013). Figure 1 depicts secondary one-dimensional compression (Head, 1994). In relation to creep deformation theories, this concept is wellknown as Hypothesis A (Jamiolkowski et al., 1985). It assumes that creep does not occur during the first phase, but happens after the primary consolidation ends. Based on this, it is supposed that the void ratio at the end of the primary consolidation phase is unique, independent of the thickness of the soil layer, drainage conditions and the time to reach the end of primary consolidation (Fatahi et al., 2013). In contrast, Hypothesis B assumes that creep takes place from the beginning, together with primary consolidation. Hence the void ratio is non-unique, but is affected by the thickness of the soil layer and drainage conditions. A number of studies have confirmed the value of Hypothesis B (Le et al., 2015), despite the need of more complex calculations of settlements (Fatahi et al., 2013). For this reason Hypothesis A is used in geotechnical practice as an initial 
approximation of the complex behavior of cohesive soils. Hypothesis B is a widely accepted assumption in creep phenomena studies (Degago et al., 2009; Watabe et al., 2012).

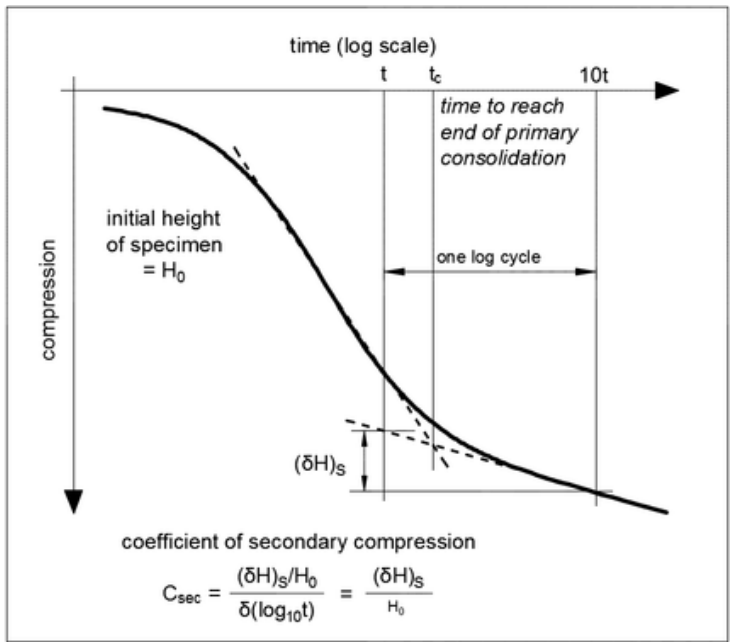

Fig.1. Determination of the secondary compression coefficient $\mathrm{C}_{\mathrm{sec}}$ (Head, 1994) and the time to reach the end of primary consolidation, if we assume creep deformation is independent of primary consolidation

This paper gives a brief overview of stateof-the-art of soil creep. The article shows various attempts at explaining the genesis of creep as well as the most common constitutional model implemented in calculation software. Selected practical issues are raised in which knowledge of creep is crucial.

\section{Genesis of creep}

The literature can be broken down into five main groups of explanations for creep mechanisms: (i) breakdown of the interparticle bonds, (ii) sliding between the soil particles, (iii) water flow from micro-pores to macropores, (iv) deformation due to structural viscosity, (v) deformation due to jumping bonds (Le et al., 2012). Figure 2 is a schematic example of clayey soils, with characteristic elements: clay particles, adsorbed water, coarse grained particles, micro- and macropores.

The described phenomena might conceivably overlap, at least in part. The first explanation of creep mechanisms relates to Terzaghi's theory of consolidation. It assumes that creep deformation takes place during pore water dissipation and the compression stress transformation to the soil structure. The process stops after all stresses are transferred. The second mechanism, in general, refers to the bonding of solid soil particle to solid soil particle. Creep deformation is due to the tangential component of the contact force of the soil particles. Additional detailed information can be found in Kuhn and Mitchell (1993). The third mechanism is based on the theory of double porosity. Owing to the presence of coarse grains, which create a primary structure with macro-pores, and fine clay mineral grains, which create a secondary structure with micro-pores, creep deformation happens due to pore water movement from microstructure (secondary structure) to macrostructure (primary structure). Next, the structural viscosity genesis of soil creep is based on the assumption that clayey soils exhibit viscosity inside their internal structure. The key factor here is water content, e.g., as absorbed water film. The last mechanism of creep is linked to the movement of atoms and molecules to a new equilibrium position, due to exceeding activation energy. As with the sliding between soil particles mechanism, this concept belongs to the strain rate mechanisms group (Kuhn and Mitchell, 1993). Additional information about structure changes can be found in a paper concerning soft clay microstructure under accelerated creep conditions (Lei et al., 2016).

\section{Dynamic of soil creep deformation}

The strain rate of creep may be variable or constant. Accordingly, Kisiel distinguishes four creep phases: 


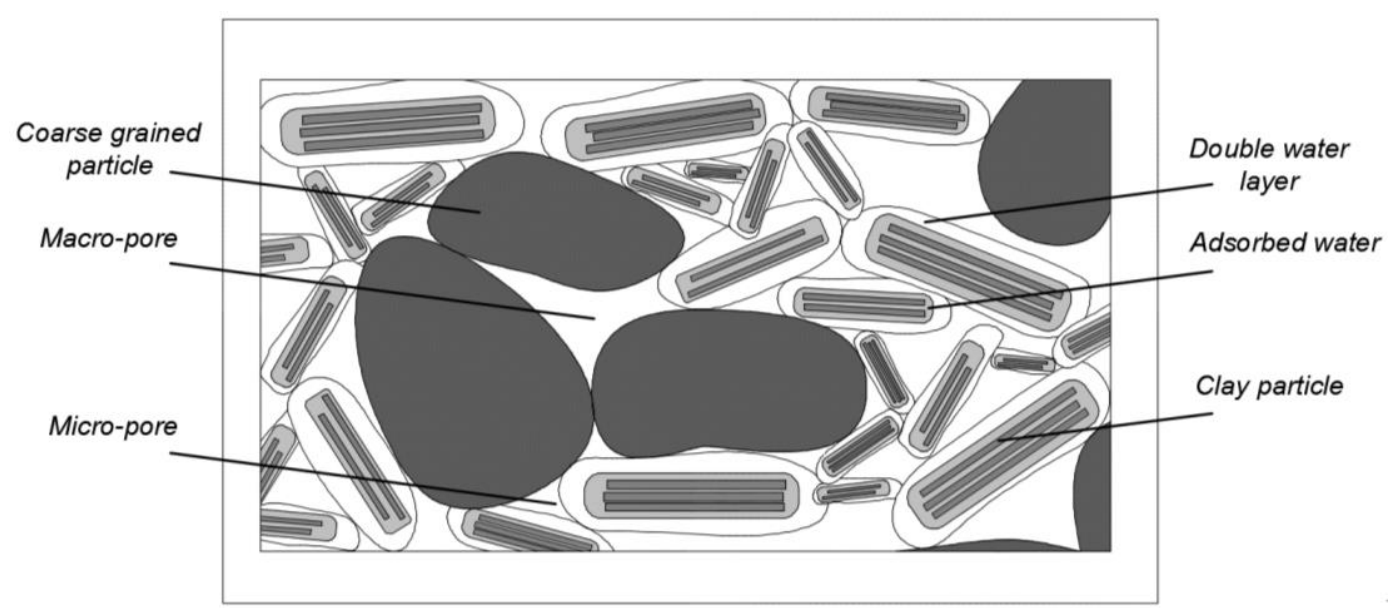

Fig.2. Schematic view of clay-water system (modified after Le et al., 2012)

(i) slight reversible strains, (ii) decelerate creep (primary creep), (iii) steady state of creep acceleration (secondary creep), (iv) phase of immediate failure (tertiary creep). These phases may occur one after another or appear separately. Furthermore, creep phases are in relation to the characteristic values of the stress, which induces specific structure change as well as soil behavior. These characteristic values are: the Tanowski strength limit $\theta_{T}$, permanent liquefaction limit $\theta_{\omega}$ and immediate liquefaction limit $\theta_{0}$ (fast and heavy nonfailure load of clay), where $0 \sim \theta_{T}<\theta_{\omega}<$ $\theta_{0}$ (Kisiel, 1982). In order to establish a correct phenomenological model, Kisiel points the following lists to be fulfilled: (i) slight reversible strains are present while the major stress are less than $\theta_{T}$, (ii) decelerate creep takes place while major stress is higher than $>\theta_{T}$ and is lower than $<\theta_{\omega}$, (iii) steady state of creep acceleration is due to major stress higher than $>\theta_{\omega}$ and less than $<\theta_{0}$, (iv) during the phase of immediate failure soil strain does not stabilize and the failure becomes faster as the stress gets closer to the value of $\theta_{0}$. The figure 3 shows the creep evolution by means of a graph showing the increase in soil strain at a time of constant stress. The author's experience with triaxial creep tests (e.g., Kaczmarek et al., 2017) confirmed Kisiel's description (1982) that soil creep dynamics is dependent on "strength reserve".

\section{Creep estimation}

The creep process is easily visible in clay soils, in which hydrophilic minerals (e.g. montmorillonite) have a dominant share. As the degree of soil overconsolidation decreases, the share of whole deformation makes longterm creeping deformations more significant. These types of soils are common in various places in the world, e.g. Leaning Tower of Pisa (Neher et al. 2003), various areas in Scandinavia (Grimstad et al., 2015), Southern Germany (Kempfert and Gebreselassie, 2006), region of Hong Kong (Yin, 1999), etc. Therefore, the issue is constantly raised anew. It is worth noting that, for practical tasks, it can be assumed that the higher the primary compression settlement, the higher the secondary compression settlement within approx. 10-30 years (Vermeer and Neher, 1999). Furthermore, Fatahi et al. (2013), on the basis of many archival records, summarize a constant relationship (called creep ratio) between the creep index $\left(\mathrm{C}_{\alpha}\right)$ and compression 


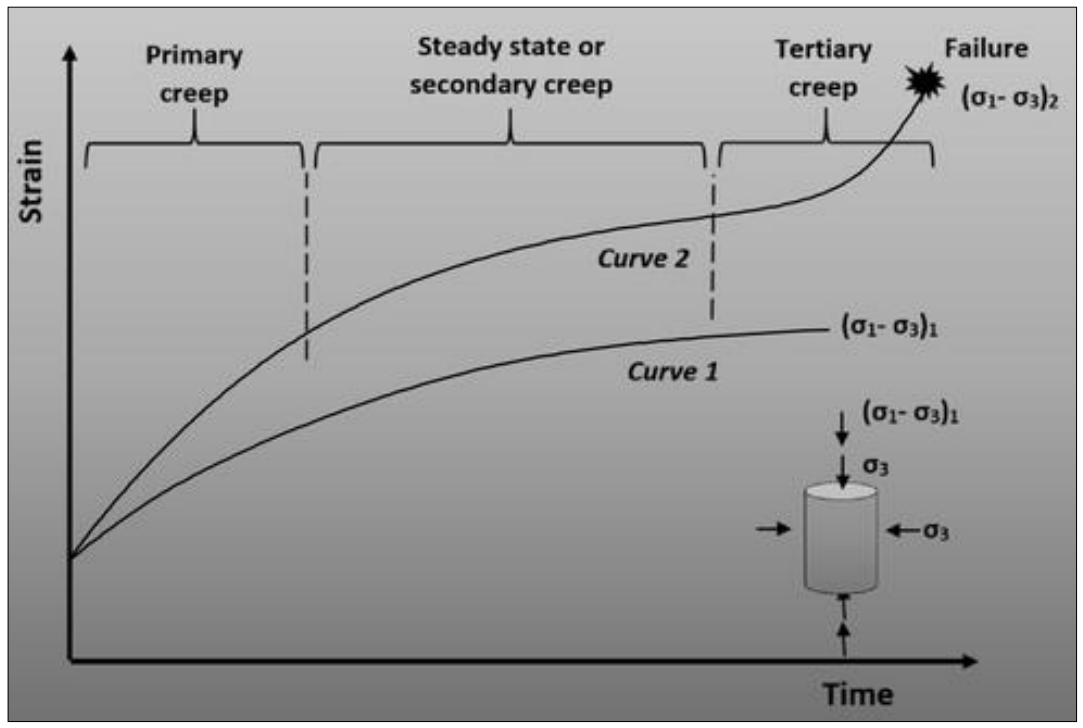

Fig.3. Different phases of creep in various stress regime. Curve 1 presents the case where major stress is small enough so that the creep change of the soil structure is decelerated. In curve 2, the creep stress leads to soil structure failure and plasticity of soil

index $\left(\mathrm{C}_{\mathrm{c}}\right)$ as $\mathrm{C}_{\alpha} / \mathrm{C}_{\mathrm{c}}=0.02-0.1$ for different types of soils. While Kempfert and Gebreselassie (2006) noted, in relation to archival research, that for soft soil this ratio can be up to 0.08 . Additionally for soft soils, Tsukada and Yasuhara (1995) estimated $\mathrm{C}_{\alpha}$ according to initial void ratio $\mathrm{C}_{\alpha}=0.0145 \mathrm{e}_{0}{ }^{1.555}$. Furthermore, Waterman and Broere (2005) suggest that for difference between modified compression index and modified swelling index, divided by modified creep index is higher than $25\left(\left(\lambda^{*}-\kappa^{*}\right) / \mu^{*}>25\right)$, creep deformation should be ignored. The relation among standard and modified indexes can be found in Grimstad et al., 2015, and some more additional information in Zhu et al., 2011. Figure 4 presents an example of $\mathrm{C}_{\alpha}$ and $\mathrm{C}_{\mathrm{c}}$ correlation for soft soil (Olga Clay; Mesri et al., 1985).

\section{Various fields of creep occurrence}

Natural slopes of escarpments and embankments display in many cases particular examples of soil creep (Zabuski, 2004; Liew et al., 2013). Those kinds of areas are natural places for slow ground movements driven by gravity, e.g. settlements (two case studies can be found in Mesri et al., 1985). Figure 5 shows various stress regimes causing soil structure changes. These regimes impact on decreasing strength parameters, and therefore on surface soil creeping deformations as well as theoretical mass movements and failure surface.

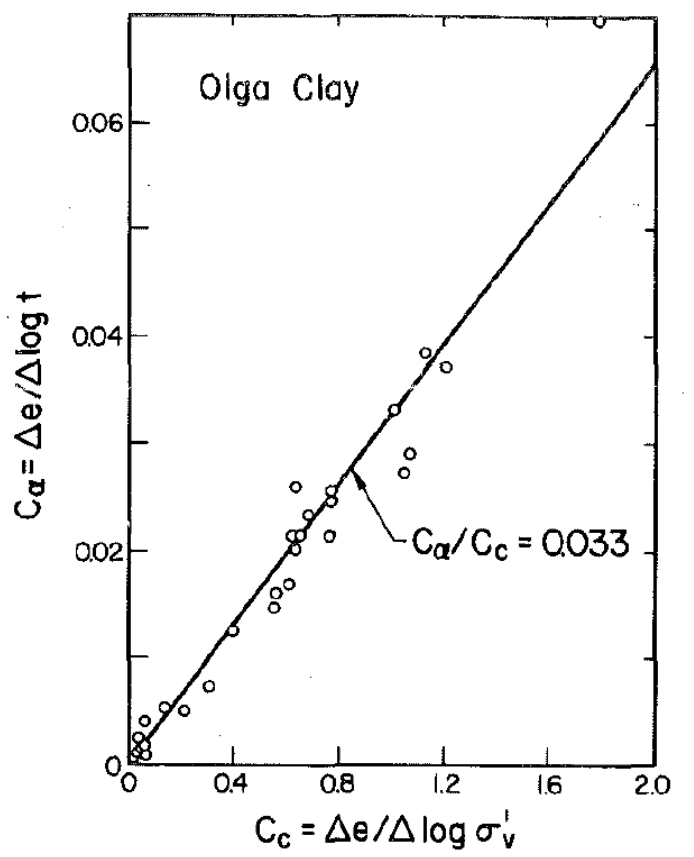

Fig.4. $\mathrm{C}_{\alpha}$ versus $\mathrm{C}_{\mathrm{c}}$ data for Olga Clay (Mesri et al., 1985) 


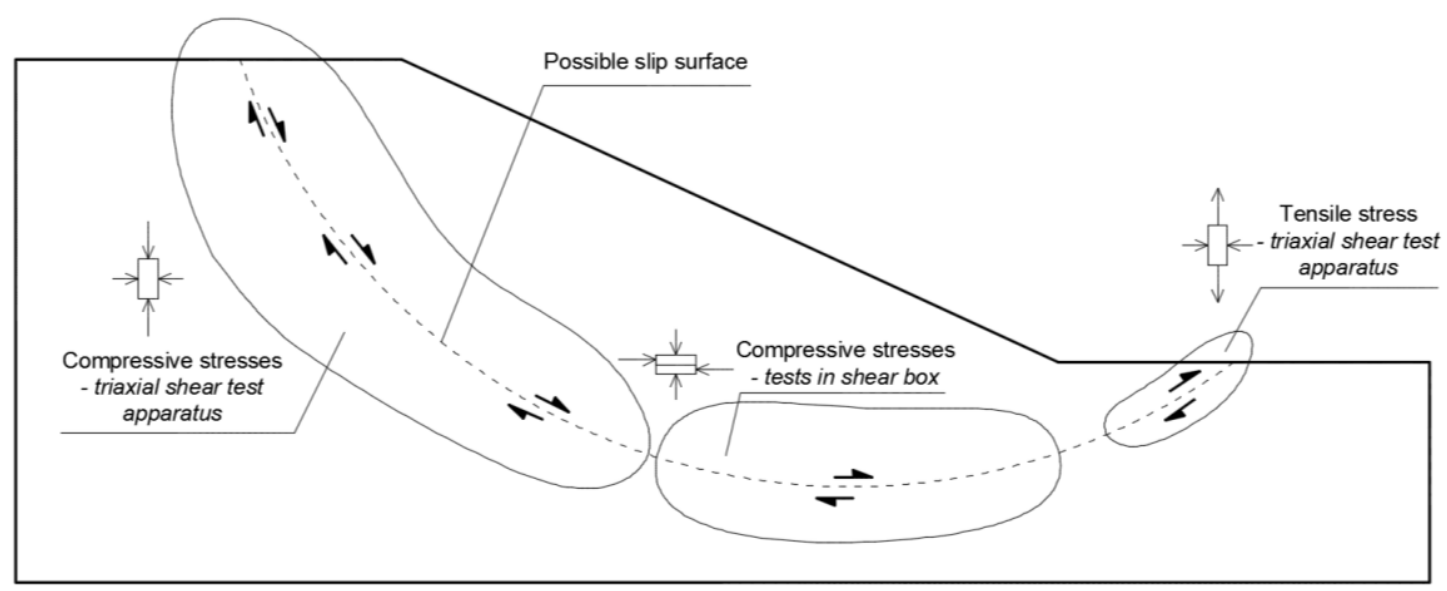

Fig.5. Various stress fields in creep soil behavior in slope stability issue with assigned laboratory tests

The phenomena of soil creep is an important issue in many cases, e.g. excavations and foundations, as is widely described by Kempfert and Gebreselassie (2006). An example of creep settlements and ground improvement techniques case studies can be found in Schweiger et al., (2013). It should be emphasized that the nature of soil properties is variable and so, for example, after heavy rain cohesion soils can become more viscous in nature. In the case of soils with high clay fraction and with high humidity, internal friction plays an important role. Behavior of soil is more sol-like, hence it can be well examined using a rheometer (Kaczmarek, 2016).

\section{Material models}

\section{Basics of material models}

It is hard to describe soil behavior which occurs as a result of variability of a material nature. Soil is a multi-phase, anisotropic material, whose response to load is non-linear and whose strains are partly reversible and partly not. Furthermore, the behavior of soil is related to the impact of load history, and change in parameters as a function of time. Hence, due to the complexity of soil features, the models used simplify soil behavior to a description of selected characteristics of soil.
This approach can be used to solve most specific geotechnical issues. The first approximation of soil attributes is mechanical models. They provide an imitation of soil behavior by using idealistic elements, i.e., Newton viscous liquid, Hooke perfect elastic body and St. Venant perfect plastic body. Linking these basic elements in series or in parallel imitates more complex non-linear soil behaviors, e.g.: Pradtl model (elastic-plastic body), Bingham model (elastic-viscoplastic body) or Kisiel model without filtration (parallel connected Maxwell and Prandtl elements) and with filtration (parallel connected Maxwell and Prandtl elements in piston; Glazer, 1985).

In order to use mechanical models (Glazer, 1985) in more sophisticated practice problems, the equations describing relations in these models were implemented in numerical software by calculation codes (Zsoil, 2014). There are various numerical methods for quantitative analysis of structure-soil interaction and groundwater issues. Among the methods commonly used are the finite element method and finite difference method, which are based on the iterative process of integrals calculation from constitution material formula. As in mechanical models, numerical models can be elementary or advanced. Hence, a numerical model can imitate soil behavior through simplification and also faithfully 
reproduce complex soil behavior. An example of a relatively simple elastic-plastic model in wide use is the Mohr-Coulomb hardening soil model. Figure 6 shows the results of numerical simulation of oedometric testing based on the example of one of the basic models: the MohrCoulomb model. It can be well observed that in the order to simplify soil behavior, the curve is made as a series of steps instead of being rounded. The calculations were performed with Plaxis software. In the case of a more advanced analysis, such as the analysis of soil creep, this model does not provide reliable solutions.

The quite universal advanced elasticplastic model for soils is the hardening soil model, but it is not adequate for creep phenomena. Moreover, the consequence of advanced numerical models is their need for many, often difficult to obtain, soil parameters. Nevertheless, creep strains need to use advanced time-dependent specific constitutive models like the Soft Soil Creep model or Elastic Visco-placitc model.

\section{Selected time-dependent material models}

In order to take into account plastic deformations, visco-plastic models are used. These models can be used to analyze soil deformation as a function of time and stress exceeding the yield boundaries (Kempfert and Gebreselassie, 2006). Commonly used is the Soft Soil Creep (SSC) model, which is in the Cam-clay model family. It takes into account soil parameters associated with the MohrCoulomb failure criterion, i.e. cohesion, friction angle, dilatancy angle. It also uses stiffness parameters, i.e. modified compression index, modified swelling index, modified creep index (Waterman and Broere, 2005).

The SSC assumption is that all inelastic strains are considered to be creep. In this case of a three-dimensional model, which is an extension of the one-dimensional model obtained from oedometric testing, total strain is defined by equation (3):

$$
\begin{aligned}
& \varepsilon=\varepsilon_{c}^{e}+\varepsilon_{c}^{c r}+\varepsilon_{a c}^{c r}=-A \cdot \ln \left(\frac{\sigma^{\prime}}{\sigma_{0}^{\prime}}\right)-B . \\
& \ln \left(\frac{\sigma_{p c}^{\prime}}{\sigma_{p 0}^{\prime}}\right)-C \cdot \ln \left(\frac{\tau_{c}+t^{\prime}}{\tau_{c}}\right)
\end{aligned}
$$

where:

$\varepsilon_{c}^{e}$ - the elastic strain during primary compression

$\varepsilon_{c}^{c r}$ - the creep strain during primary compression

$\varepsilon_{a c}^{c r}$ - the creep strain after primary compression $\tau_{c^{-}}$- the intercept with the time axis of the straight creep line t'- effective creep time

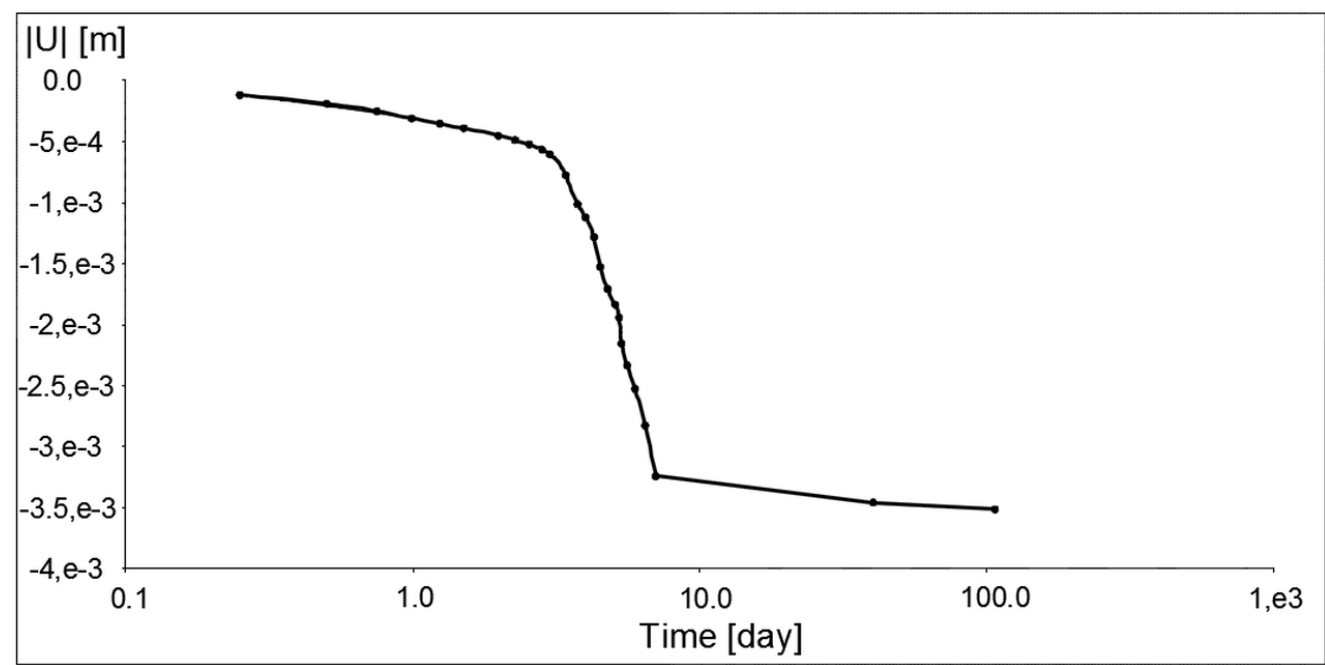

Fig.6. Example of using too elementary numerical model to simulate oedometer laboratory test 
and:

$$
\begin{aligned}
& \varepsilon_{c}^{e}=\frac{C_{r}}{\left(1+e_{0}\right) \cdot \ln 10}=\left(\frac{\kappa}{V}\right) \\
& \varepsilon_{c}^{c r}=\frac{\left(C_{c}-C_{r}\right)}{\left(1+e_{0}\right) \cdot \ln 10}=\left(\frac{\lambda-\kappa}{V}\right) \\
& \varepsilon_{a c}^{c r}=\frac{C_{\alpha}}{\left(1+e_{0}\right) \cdot \ln 10}=\left(\frac{1}{r_{s}}\right)
\end{aligned}
$$

This model can be used to mimic logarithmic compression soil behavior, secondary (time-dependent) compression and memory of pre-consolidation stress. This model follows the concept of the time resistance concept introduced by Janbu (1969). A detailed explanation of the SSC model can be found in Vermeer and Neher 1999 and in Neher et al. 2001. It should be highlighted that the SSC model assumes a constant creep rate with time and stress level (modified creep index is a constant value), and this leads to over estimating the predicted long term deformations (Fatahi et al., 2013). Nonetheless as shown in case studies (e.g. Grimstad et al., 2015), this model gives satisfactory results in creep deformation approximation.

The SSC as well as other one dimensional visco-plastic models implement Perzyna's elasto-visco-plastic theory for multidimensional stress space (Perzyna, 1963). Perzyna's concept assumed that visco-plastic strains occur when stress reaches the yield surface. The visco-plastic strain rate is determined by the relation between effective stress and present static yield stress. An extension of this model came in the OlszakPerzyna theories (Olszak and Perzyna, 1966), in which unlike in the previous one the yield surface changes over time due to creep behavior. These theories constituted the basis for future multi-dimensional expressions of time-dependent soil behavior as well as the numerical implementation.

As stated in first section above (Basic definition of creep), the generally accepted assumption is that excess pore water pressure dissipation and creep occur simultaneously and so there is a joint impact on compression. Analyzing long term settlements, the strain-log time relation is in many cases nonlinear (Yin, 1999). For simplicity and practical application for a particular soil, engineers compute the creep settlement using a constant creep coefficient (e.g. Vermeer and Neher, 1999). The constant creep coefficient is involved in the soft soil creep material model. Yin (1999), based on the consolidation date, proposed a sophisticated nonlinear and non-constant creep function that can analyze the stress-strain relation more realistically for the purpose of long-term settlement prediction. This elastic visco-plastic (EVP) model is based on the framework of the modified Cam-clay model, but there are clear key differences relating to nonlinear variations of the creep coefficient with the effective stress and time. It is a challenging task to determine the parameters for this EVP model (Le, Fatahi and Khabbaz, 2015). That is why Le, Fatahi and Khabbaz (2015) proposed a new numerical solution to determine the EVP model parameters, implementing a trust-region reflective least square optimization algorithm and the finite difference scheme to simulate soft soil stressstrain behavior, based on laboratory tests and a field case. This approach can serve as a practical tool to enhance the application of the nonlinear EVP model (Le, Fatahi and Khabbaz, 2015; Azari, Fatahi and Khabbaz, 2015).

Le, Fatahi and Khabbaz (2015) explained that the proposed optimization method minimizes the viscosity contribution in the reference time-line, and increases the accuracy of the model parameters by utilizing all laboratory results of several loading stages during and after dissipation of the excess pore water pressure. Furthermore, the creep phenomena during compression can also be observed by variations in the creep parameters (e.g. creep coefficients, creep strain rates) at different depths and times (Le and Fatahi, 2016). It should be highlighted that creep 
properties are affected by effective stress, which changes with depth and time. Hence, as Le and Fatahi (2014) describe, as effective stress increases with depth and time, the creep related parameters decrease.

Numerical calculation studies of Le et al. (2015) based on the elastic visco-elastic nonconstant creep model have found that a thicker soil layer has lower creep parameters and therefore a slower creep strain rate. Furthermore, Le at al. (2015) clarify that although the thicker soil layer has a lower creep strain rate, the time required to achieve the end of primary consolidation is much higher than for the thinner soil layer. This is why the compression of the thicker soil layer at the end of the primary consolidation is greater than it is with the thinner soil layer. The variation of the creep parameter during the dissipation process is notable (Le et al., 2015). Thus the simplifying assumption of a constant creep coefficient during the dissipation process as established in earlier studies (e.g. Vermeer and Neher, 1999) is realistic (Le et al., 2015).

One important practical aspect needing particular attention with regard to creep calculation is preloading for ground improvement. Estimation of pore water pressures as well as settlement variations with depth can be significantly influenced by creep consolidation. Azari, Fatahi and Khabbaz (2015) performed sophisticated analyses of preloading combined with vertical drains. Based on this study, Azari, Fatahi and Khabbaz (2015) found that different OCR profiles in the disturbed and transition zones result in various viscoplastic strain rates and creep strain limits. The selection of the OCR profile in the disturbed and transition zones has considerable effects on determining the postconstruction settlement.

\section{Outlook}

The complexity of soil creep arises out of many factors, often varying greatly between regions. The key factors responsible for the complexity of the cohesive soils characteristics are: clay particle fraction in soil, natural humidity, mineral composition and geological history (Kumor and Kumor, 2017). Furthermore, generally speaking, the conditions that trigger soil creep movement are variable, e.g. inconstant stress acting on soil (where constant load is not the same due to variable effective stresses), different structural soil features (e.g. glacitectonically involved Mio-Pliocene clays from the Warsaw and Bydgoszcz areas, as well as clay stone colluvium from the southern part of Poland). Because of this complex conditions of creep soil deformation, which is three dimensional issue, analysis in the triaxial apparatus would be required.

From the very beginning of creep triaxial testing there were a pragmatic wish, in respect of geotechnical design, to reduce the time duration of testing. One example of this approach is the creep triaxial test using cylindrical soil samples, which have a ratio of height to diameter of $1: 1$. The core of this method is based on step change of the strain rate during the occurrence of creep (Gudehus, 1979). As a result, the viscosity index of a specific soil is obtained (Gudehus, 1979; 2011). The literature contains case studies in drained and undrained conditions, using triaxial apparatus, with effort of onedimensional theories adjustment for threedimensional stress state (e.g. Zhu et al., 2011; Wang et al., 2014). Studies of Ye et al. (2013) found that the creep time under drained condition is longer than in the undrained condition. Furthermore, Luo and Chen (2014) showed that under the same deviatoric stress, the axial strain of the undrained creep test is smaller than in the drained creep test. Luo and Chen (2014) explained that, under the undrained condition of the triaxial creep test, deformation is generated only by the creep; however, during the drained triaxial test, deformation is caused by consolidation and 
creep together. Another interesting direction of research is an attempt to analyze unsaturated soil due to creep phenomena (e.g. Lai et al., 2014). Furthermore, Ye et al. (2013) present study results of soil creep and the soil dynamic load relation. The measurements of deformation velocity and direction of strain vectors are a global indicator of creep microstructure changes. Hence, lateral and horizontal strain measures are wide ranging issues. Local strain transducers harnessing the Hall effect (even in a range from $0.001 \%$ to $1 \%$ ) can deliver highly accurate measurements (Clayton and Khatrush, 1986; Bogusz and Witowski, 2015). Figure 7 presents a horizontal strains sensor - the sensor holder was designed and manufactured on a threedimensional printer - based on Hall effects dedicated for a specified sample size.

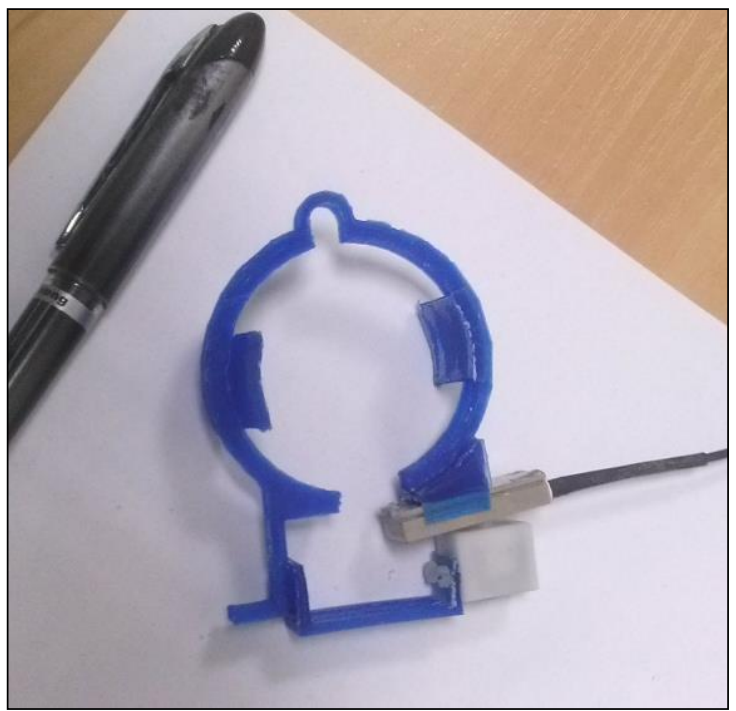

Fig.7. Horizontal strains sensor (its holder was designed and manufactured on a three-dimensional printer) based on Hall effects dedicated for a specified sample size

One of the tools that can be used to make comparisons of displacements of different areas is the hodograph construction (map of velocity; Glazer, 1985). Based on many spatially variable data, multi-factor correlations can be determined. Furthermore, numerical simulations of laboratory tests (e.g. oedometric, triaxial compression tests) can be validated, and therefore enable further advanced analysis such as creep strains during consolidation testing (Le, Fatahi and Khabbaz, 2015) or stress distribution in samples (Havel, 2004). One piece of creep research work where numerical calculations were used to determine temperature distribution inside the oedometer cell as a function of time is a study performed by $\mathrm{Li}$ et al. (2016). In this investigation, innovative temperature controlled consolidation tests were used. The results were applied in pile-high sensitive soil interaction analysis in Sweden.

Due to the presence of clay soil in urban areas and as a base of engineering structures (e.g. dams), it is crucial to produce reliable characterization of soil displacements, which result from among others long-term creep, in particular in the context of long-term safety guarantees and the long service life of engineering structures.

\section{References}

Azari B., Fatahi B., Khabbaz H. (2015) Assessment of the elastic-viscoplastic behavior of soft soils improved with vertical drains capturing reduced shear strength of a disturbed zone. International Journal of Geomechanics 16, 1, B4014001 1-15.

Bogusz W., Witowski M. (2015) Validation of the Hardening Soil small model in triaxial soil test with local strain transducers. Inżynieria Morska i Geotechnika 3, 262 266.

Clayton C.I.R., Khatrush S. A. (1986) A new device for measuring local axial strains on triaxial specimens. Geotechnique 36, 4, 593-597.

Degago S.A., Grimstad G., Jostad H.P., Nordal S. (2009) The non-uniqueness of the endof-primary (EOP) void ratio effective stress relationship, [In:] Proc. 17th Inter. Conference on Soil Mechanics and 
Geotechnical Engineering, Alexandria, Egypt, 324-327.

Dobak P. (1986) Zmiany odkształcalności gruntów wywołane procesami inżyniersko - geologicznymi w rejonie Kopalni Węgla Brunatnego „Bełchatów”. PhD dissertation, University of Warsaw.

Dobak P. (1999) Rola czynnika filtracyjnego w badaniach jednoosiowej konsolidacji gruntu. Wyd. CPPGSMiE PAN.

Dobak P., Gaszyński J. (2015) Evaluation of soil permeability from consolidation analysis based on Terzaghi's and Bio's theories. Geological Quarterly 59, 2, 373381.

DOI: http://dx.doi.org/10.7306/gq.1197.

Fatahi B., Le T. M., Le M. Q., Khabbaz H. (2013) Soil creep effects on ground lateral deformation and pore water pressure under embankments. Geomechanics and Geoengineering $\quad 8, \quad 2, \quad 107-124$. DOI: 10.1080/17486025.2012.727037.

Glazer Z. (1985) Mechanika gruntów. Wyd. Geologiczne.

Grimstad G., Mehli M., Degago, Samson A. (2015) Creep in Clay During the First Few Years After Construction. [In:] Proc. 6th Int. Sym. on Deformation Characteristics of Geomaterials, Buenos Aires, 915-922.

Grimstad G., Haji Ashrafi M.A., Degago S.A., Emdal A., Nordal S. (2016) Discussion of "Soil creep effects on ground lateral deformation and pore water pressure under embankments". Geomechanics and Geoengineering 11, 1, 86-93. DOI: 10.1080/17486025.2014.985338.

Gudehus G. (1979) Näherungsformeln und Geschwindigkeiten und Kräfte in fließenden bindigen Boden. Freiberger Forschungsheft 617, 41-55.

Gudehus G. (2011) Physical Soil Mechanics. Springer.

Havel F. (2004) Creep in soft soils. PhD dissertation, Norwegian University of Science and Technology in Trondheim.
Head K.H. (1994) Manual of Soil Laboratory Testing. Volume 2: Permeability, Shear Strength and Compressibility Tests. John Wiley and Sons, Second Edition,

Jamiolkowski M., Ladd, C.C., Germaine, J.T., Lancellolta, R. (1985) New developments in field and laboratory testing of soils. [In:] Proc. 11th Int. Conf. on Soil Mechanics and Foundation Engineering, San Francisco, 57-153.

Janbu N. (1969) The resistance concept applied to deformations of soils. [In:] Proc. $7^{\text {th }}$ Int. Conf. Soil Mechanics Foundation Engineering, Mexico City, 191-196.

Kaczmarek Ł. (2016) Rheometer use in analysis of soil creep behavior. [In:] Proc. 16th International Multidisciplinary Scientific GeoConference SGEM 2016 Science and Technologies in Geology, Exploration and Mining, Vol. III, Albena, 237-244.

Kaczmarek Ł., Dobak P., Kiełbasiński K. (2017) Preliminary investigations of creep strain of Neogene clay from Warsaw in drained triaxial tests assisted by computed microtomography. Studia Geotechnica et Mechanica (in press).

Kempfert H., Gebreselassie B. (2006) Excavations and Foundations in Soft Soils. Springer.

DOI: 10.1007/3-540-32895-5.

Kuhn M., Mitchell J. (1993) New Perspectives on Soil Creep. Journal of Geotechnical Engineering 119, 3, 507-524. DOI: 10.1061/(ASCE)07339410(1993)119:3(507)

Kumor M.K., Kumor Ł.A. (2017) Geotechniczne zagadnienia fundamentowania w iłach ekspansywnych. [In:] Analizy i doświadczenia w geoinżynierii (ed. J. Bzówka, M. Łupieżowiec). Wydawnictwo Politechniki Śląskiej, Gliwice, 281-301.

Kisiel I. (1982) Mechnika skał i gruntów. PWN. 
Lai X.L., Wang S.M., Ye W.M., Cui Y.J. (2014) Experimental investigation on the creep behavior of an unsaturated clay. Canadian Geotechnical Journal 51, 6, 621-628.

DOI: $10.1139 / \mathrm{cgj}-2013-0064$.

Le T.M., Fatahi B. (2016) Trust-region reflective optimisation to obtain soil viscoplastic properties. Engineering Computations 33, 2, 410-442.

Le T.M., Fatahi B., Disfani M., Khabbaz H. (2015) Analyzing consolidation data to obtain elastic viscoplastic parameters of clay. Geomechanics and Engineering 8, 4, 559-594.

DOI: 10.12989/gae.2015.8.4.559.

Le T. M., Fatahi B., Khabbaz H. (2012) Viscous Behaviour of Soft Clay and Inducing Factors. Geotechnical and Geological Engineering 30, 5, 1069-1083. DOI: 10.1007/s10706-012-9535-0.

Le T.M., Fatahi B., Khabbaz H. (2015) Numerical optimisation to obtain elastic viscoplastic model parameters for soft clay. International Journal of Plasticity 65, 1-21. DOI: 10.1016/j.ijplas.2014.08.008.

Lei H., Lu H., Wang X., Ren Q., Li B. (2016) Changes in Soil Micro-Structure for Natural Soft Clay under Accelerated Creep Condition. Marine Georesources and Geotechnology, 365-375. DOI: $10.1080 / 1064119 X .2015 .1010669$.

Luo Q., Chen X. (2014) Experimental Research on Creep Characteristics of Nansha Soft Soil. The Scientific World Journal 5:968738. DOI: 10.1155/2014/968738.

Li Y., M. Karstunen M. Karlsson, Dijkstra J. (2016) Evaluation of Temperature Controlled Oedometer Test Apparatus. [In:] Proc. 1st International Conference on Energy Geotechnics, Kiel, 623-627.

Liew S.S., Gue S.S., Wong C.J. (2013) Road Construction in Soil Creep Areas. [In:] Proc. JKR Sabah Seminar: "Love Our Road”, Kota Kinabalu, 1-19.
Mesri G., Choi Y.K. (1985) Settlement Analysis of Embankments on Soft Clays. Journal of Geotechnical Engineering 111, 4, 441-64.

Neher H.P., Wehnert M., Bonnier P.G. (2001) An evaluation of soft soil models based on trail embankments. [In:] Proc. 10 ${ }^{\text {th }}$ Inter. Conf. on Computer Methods and Advances in Geomechanics, Tucson, 373-378.

Neher H.P., Vogler U., Vermeer P.A., Viggiani C. (2003) 3D creep analysis of the Leaning Tower of Pisa. [In:] Proc. Int. Workshop on Geotechnics of soft soil, theory and praxis, Noordwijkerhout, 607-612.

Olszak W., Perzyna P. (1966) The constitutive equations of the flow theory for a nonstationary yield condition. [In:] Applied Mechanics, Proc. 11th Int. Congress of Applied Mechanics (ed. H. Görtler), 545-553.

Schweiger H., Ikhya I., Tschuchnigg F. (2013) Application of Numerical Methods for Estimating Settlements Due to Consolidation and Creep - Two Case Histories. Poromechanics V, 1364-1371. DOI: $10.1061 / 9780784412992.163$

Perzyna P. (1963) The constitutive equations for rate-sensitive plastic materials. Quarterly of Applied Mathematics 20, 321-332.

Tsukada Y., Yasuhara K. (1995) Scale effects in one-dimensional consolidation of clay. [In:] Proc. Int. Sym. on Compression and Consolidation of Clayey Soils, Hiroshima, 211-216.

Vermeer P.A., Neher H. P. (1999) A soft soil model that accounts for creep. [In:] Proc. Int. Sym. "Beyond 2000 in Computational Geotechnics", Amsterdam and Rotterdam, 249-261.

$\mathrm{Vu}$ Cao Minh (1977) One dimensional consolidation of soils ta king creep into account. Arch. Hydrotechniki.

Wang Y.F., Zhou Z.G., Cai Z.Y. (2014) Studies about Creep Characteristic of Silty Clay on Triaxial Drained Creep Test. 
Advances in Civil and Industrial Engineering IV, 580, 355-358. DOI:10.4028/www.scientific.net/AMM. 58 0-583.355.

Watabe Y., Udaka K., Nakatani Y., Leroueil S. (2012) Long-term consolidation behavior interpreted with isotache concept for worldwide clays. Soils Found 52, 449-464.

Waterman D., Broere W. (2005) Practical application of the soft soil creep - Part III. Plaxis Benchmarking, 22, http://kb.plaxis.nl/publications.

Ye Y., Zhang Q., Cai D., Chen F., Yao J., Wang L. (2013) Study on New Method of Accelerated Clay Creep Characteristics Test. [In:] Proc. 18th Int. Conf. on Soil Mechanics and Geot. Eng., Paris, 461-464.
Yin J.H. (1999) Non-linear creep of soils in oedometer tests. Geotechnique 49, 5, 699707.

Zabuski L. (2004) Prediction of the slope movements on the base of inclinometric Measurements and numerical calculations. Polish Geological Institute Special Papers 15: 29-38.

Zhu J., Zhao Y., Yin J. (2011) Undrained Creep Behavior of a Silty Clay in Triaxial Tests. Instrumentation, Testing, and Modeling of Soil and Rock Behavior 222, 139-146. DOI: 10.1061/47633(412)19.

Zsoil (2014), Manual Theory, Z_Soil PC v 2014, Zace Services, Lousanne. 